\title{
Relationship Between Daily Rumination Time, Physical Activity, Estrus and Metabolic Changes in Dairy Cows
}

\author{
Răzvan Nicolae MĂLĂNCUȘi ${ }^{*}$, Cristina Maria MĂLĂNCUȘ² \\ ${ }^{1}$ University of Agricultural Sciences and Veterinary Medicine Iași, Romania \\ Faculty of Veterinary Medicine, Department of Internal Medicine \\ E-mail: razvanmalancus@gmail.com \\ ${ }^{2}$ University of Agricultural Science and Veterinary Medicine Iași, Romania \\ Faculty of Veterinary Medicine, Department of Veterinary Obstetrics and Andrology \\ *corresponding author: razvanmalancus@gmail.com
}

Bulletin UASVM Veterinary Medicine 73(2) / 2016,

Print ISSN 1843-5270; Electronic ISSN 1843-5378

DOI:10.15835/buasvmcn-vm: 11685

\begin{abstract}
The present study attempted to ascertain whether there is any connection between reduced daily rumination time and increased physical activity of the animals, on the one hand, and the presence of estrus or metabolic disorders in dairy cows, on the other hand. It has been observed that of the total of 168 cows, 55 (32.73\%) showed decreased daily rumination time, 57 cows (33.92\%) had specific manifestations for estrous period, while 25 cows $(14.88 \%)$ showed both decreased daily rumination time and the presence of estrus. Statistical assessment of the data demonstrated a highly significant correlation between these two factors, with a p-value $<0.05(p=0.0369)$. Regarding the correlation between increased physical activity, found in 40 cows (23.80\%) and the presence of estrus, observed in 57 cows (33.92\%) this one is extremely statistically significant with a p-value $<0.001(p=0.0005)$, the combination of increased physical activity and estrus being detected in a total of 23 cows (13.69\%). Thus, of 168 dairy cows taken into the study, 37 (22.02\%) showed an association between decreased daily rumination time and increased physical activity, resulting in an extremely statistically significant correlation between the combination of the two events and the presence of estrus in cows, with a p-value $<0.001$ ( $p=0.0003$ ). Metabolic disorders were found in a total of 12 dairy cows (7.14\%), the association between decreased daily rumination time and increased physical activity being not statistically correlated with the development of metabolic disorders, $p=0.4676$. It remains to be observed if a correlation between the association of decreased daily rumination time and increased physical activity with the presence of metabolic disorders exists.
\end{abstract}

Keywords: dairy cows, estrus, physical activity, rumination.

\section{INTRODUCTION}

Rumination is a cyclical process characterized by regurgitation, remastication, and reswallowing. An important function of rumination is to facilitate digestion, particle size reduction, and subsequent passage from the reticulorumen, maintaining high levels of feed intake. Furthermore, rumination increases saliva secretion and improves rumen functionality because saliva aids in buffering the volatile fatty acids produced by microbial digestion (Beauchemin, 1991).

Rumination time (RT) is an appropriate parameter for early identification of metabolic disorders such as ruminal acidosis. Saliva secretion and rumen health are closely associated with daily RT (Maekawa et al., 2002). While some measurements of RT implemented by technical methods like pressure transducers (Kaske et al., 
2002) or piezo disks integrated within a cow's halter (Yang and Beauchemin, 2006), are mostly invented for research purposes, the microphonebased system (HR-Tag, SCR Engineers Ltd., Netanya, Israel) became commercially available for automatic recording of RT data (Reith et al., 2014). Rejection of feed boluses and mastication produce sounds that are registered by the acoustic sensor (Burfeind et al., 2011) and can be separated from sounds related to eating (Adin et al., 2009). Schirmann et al. (2009) and Burfeind et al. (2011) found a high correlation $(r=0.88$ and $r=0.93$, respectively) between RT obtained from the HRTag and visual observation.

Rumination time is mainly used in dairy farms to predict impending metabolic disorders and calving (Soriani et al., 2012, 2013), and provides useful information to control feeding strategies and rations concerning its structure and components. Today, there are commercial systems available to record both RT and activity behavior every $2 \mathrm{~h}$ for the individual cow in the herd (Soriani et al., 2013). In validation studies, researchers who compared data for RT generated by these systems with those obtained by visual observation confirmed the suitability of these systems to accurately monitor daily RT in a practical setting on farms (Burfeind et al., 2011).

Although RT can be used for monitoring the metabolic health of dairy cows, it is not known whether RT is influenced by fertility and reproductive management routines. A change that seems to be clearly associated with estrus behavior and that is pronounced in many cows is the increase in physical activity.

The present study attempted to ascertain whether there is any connection between reduced daily rumination time and increased physical activity of the animals, on the one hand, and the presence of estrus or metabolic disorders in dairy cows, on the other hand.

The present study was considered necessary to assess the correlation between the presence of estrus in cows and the association of the following factors: decreased daily rumination time and increased physical activity, all the variables being recorded using a device equipped with sensors or microphone for recording the rumination sounds, the data being transferred to a specialized program.
Also, the study tried to observe if there is a correlation between decreased daily rumination time and increased physical activity with the presence of metabolic disorders, or the two variables correlate strictly with the presence of estrus in cows.

\section{MATERIALS AND METHODS}

The study was conducted at a farm near Liverpool, UK on a herd of 168 Holstein Friesian dairy cows over a period of one month. The dairy cows were housed in free stall shelters; the feeding of the cows was made ad libidum, while the milking system was automated.

Monitoring rumination and physical activity was performed using HR neck collar (SCR), a rumination monitoring system combined with a unique motion sensor that uses sounds picked up by a microphone that is in tight contact to the cow's neck to measure the rumination time (RT). This system is integrated in commercial activity tags (Hi-Tag) and is named HR-Tag. The collar also permits storing data regarding physical raw activity or weighted activity through its sensors. The recorded data is downloaded to and stored in the herd computer after each milking or any time a cow passes under a tag reader, and is available as individual or group reports, produced by the herd management software (Data Flow). Rumination is recognized by analyzing the chewing sounds, and excluding the sounds related to eating. Data is stored in "2 hours cells", in 2 minutes resolution (Doron and Ran, 2010).

The presence of estrus in dairy cows has been assessed by cyclic activity evaluation generated by Data Flow software and confirmed by physical examination of the animals.

Metabolic evaluation was done by biochemical examination conducted by IDEXX VetTest $\AA$ Chemistry Analyzer which detects key biochemical parameters for 18 species. The principle of the method is based on dry-slide technology which uses layers and washes to remove impurities for the most reliable results and spectrophotometry. In this study, the following parameters were evaluated: alanine aminotransferase, aspartate aminotransferase, gamma glutamyl transferase, alkaline phosphatase, alkaline reserve, albumins and total proteins.

Data regarding the daily rumination times, physical activity and the presence of estrus in 
dairy cows were recorded in contingency tables by entering values reduced to 0 and 1 . Thus, decreased daily rumination times ( $<500 \mathrm{~min} /$ day) has been noted as 1 and normal or increased daily rumination time has been noted as 0 . Increased physical activity ( $>45$ minutes / 2 hours period) in dairy cows has been noted as 1 and decreased or normal physical activity as 0 . Regarding the presence or the absence of estrus, these have been noted as 1 , respectively 0 . In a similar manner has been proceeded for the metabolic disorders, their presence being noted as 1 and their absence as 0 .

Since the study aimed to observe whether there is a correlation between the presence of estrus and the exact combination of the factors represented by decreased daily rumination time and increased physical activity in dairy cows or the latter can also be seen in various metabolic disorders, the exact combination represented by decreased daily rumination time and increased physical activity has been marked as 1 and the remaining possible combinations as 0 .

The recorded data has been statistically interpreted using Fisher's exact and PAWS 18 software which generated the cross tables.

\section{RESULTS AND DISCUSSION}

The data obtained using the Hi Tag neck collar have been recorded both individually and from the whole herd. One hundred sixty-eight dairy cows providing relevant data, without breaks in recording, were taken into research.

Rumination is a cyclical process characterized by regurgitation, remastication, and reswallowing. Since visual observation to measure RT is labor intensive, indirect methods of monitoring rumination were proposed. Some were based on jaw-motion-detecting devices in a halter (Luginbuhl et al., 1987). These devices were effective at measuring rumination, differentiating jaw movements associated with chewing or ruminating behavior (Beauchemin et al., 1989) but may be uncomfortable for the animals. In our study a new system was adopted to measure the RT in dairy cows (HR-Tag rumination monitoring system, SCR Engineers Ltd.). This device was described and validated by Schirmann et al. (2009), indicating its accuracy for monitoring rumination behavior in dairy cows and its usefulness in research and commercial applications (Soriani et al., 2012).
The system was used in previous research (Adin et al., 2009; Burfeind et al., 2011; Schirmann et al., 2011). Detection of estrus has been identified as one of the primary causes of reduced reproductive performance in dairy cows. Technological progress has led to the development and application of sensor-based monitoring systems that continuously monitor and record detailed information, and use these data to diagnose the status of the cow (sick or healthy, in estrus, etc.). Although measuring activity by pedometers is thoroughly investigated as an indicator of estrus (Ranasinghe et al., 2010; Yániz etal., 2006), only few data on activity measurement by means of acceleration systems attached to the neck collar are available in the literature.

Previous studies have revealed that decreased daily rumination time is related to the presence of estrus (Reith and Hoy, 2012) and also that an increase in physical activity correlates with the presence of estrus in dairy cows (Berka et al., 2004; Reith et al., 2014), but the specific combination of these factors has not been demonstrated.

Validation of the previous obtained results by other authors has been done by assessing the correlations between decreased daily rumination time and the presence of estrus, or increased physical activity and the presence of heat in dairy cows.

It has been observed that of the total of 168 cows, 55 (32.73\%) showed decreased daily rumination time, 57 cows $(33.92 \%)$ had specific manifestations for estrous period, while 25 cows (14.88\%) showed both decreased daily rumination time and the presence of estrus. Statistical assessment of the data demonstrated a highly significant correlation between these two factors, with a p-value $<0.05(\mathrm{p}=0.0369)$ (Tab. 1).

Tab. 1. The association between decreased daily rumination time (DRT) and the presence of estrus (E)

\begin{tabular}{|c|c|c|c|c|}
\hline \multicolumn{5}{|c|}{ Count } \\
\hline & & \multicolumn{2}{|c|}{ DRT } & \multirow{2}{*}{ Total } \\
\hline & & 0 & 1 & \\
\hline \multirow{2}{*}{$\mathrm{E}$} & 0 & 81 & 32 & 113 \\
\hline & 1 & 30 & 25 & 55 \\
\hline \multicolumn{2}{|c|}{ Total } & 111 & 57 & 168 \\
\hline
\end{tabular}


Regarding the correlation between increased physical activity, which was observed in 40 cows $(23.80 \%)$ and the presence of estrus, observed in 57 cows $(33.92 \%)$ there is an extremely significant statistical association, with a p-value $<0.001$ (p $=0.0005)$. Both increased physical activity and estrus was detected in 23 cows (13.69\%) (Tab. 2).

Tab. 2. Association between increased physical activity in dairy cows (PA) and the presence of estrus (E)

\begin{tabular}{|c|c|c|c|c|}
\hline \multicolumn{5}{|c|}{ Count } \\
\hline & & \multicolumn{2}{|c|}{ PA } & \multirow{2}{*}{ Total } \\
\hline & & 0 & 1 & \\
\hline \multirow{2}{*}{$\mathrm{E}$} & 0 & 94 & 34 & 128 \\
\hline & 1 & 17 & 23 & 40 \\
\hline \multicolumn{2}{|c|}{ Total } & 111 & 57 & 168 \\
\hline
\end{tabular}

The most probable reason for increased activity during estrus might be the release of estrogens starting in the pre-estrus period. Lopez et al. (2004) found a significant correlation between estradiol concentration, duration of estrus, and estrous behavior. Maximum circulating hormone concentrations were recorded one day before estrus (Lopez et al., 2004;, Reith et al., 2014) or between $16 \mathrm{~h}$ before and $9 \mathrm{~h}$ after estrus (Mondal et al.,2006).

The opposite temporal pattern was found for RT. Relating to earlier observations (Reith and Hoy, 2012), we were able to confirm that estrual cows spent significantly less time chewing.

The current study showed that RT was influenced by the onset of estrus in cows. Daily RT quantifies behavioral changes manifested by increased activity and restlessness and also reduced lying time (Brehme et al., 2006), and decreased milk yield and feed intake associated with a decrease in body weight (Maltz et al., 1997; Reith et al., 2014).

Validating the results of previous studies make a thorough assessment of decreased rumination time and increased physical activity association, in the presence of estrus in dairy cows (Lindgren, 2009).

Thus, of 168 dairy cows taken into the study, in $37(22.02 \%)$ we observed an association between decreased daily rumination time and increased physical activity, resulting in an extremely statistically significant correlation between the combination of these two events and the presence of estrus in cows, with a p-value $<0.001$ ( $p=$ 0.0003) (Tab. 3).

Tab. 3. Association between decreased daily rumination time and increased physical activity (DRT/PA) with the presence of estrus in dairy cows (E)

\begin{tabular}{rcccc}
\hline \multicolumn{5}{c}{ Count } \\
\hline & & \multicolumn{3}{c}{$\mathrm{E}$} \\
\cline { 2 - 5 } & & 0 & 1 & Total \\
\hline \multirow{2}{*}{ DRT/PA } & 0 & 96 & 35 & 131 \\
\cline { 2 - 5 } & 1 & 15 & 22 & 37 \\
\hline Total & & 111 & 57 & 168 \\
\hline
\end{tabular}

But the purpose of the study was to observe if the specific combination of increased physical activity and decreased daily rumination time is strictly associated with the presence of estrus in dairy cows or may be also associated with the presence of metabolic disorders, which have been diagnosed by investigating blood biochemical parameters.

One of the factors that reduces RT is inflammation. There are several models frequently used to induce inflammation, one of those being represented by the lipopolysaccharides (LPS) challenge, which may mimic reduced concentrations of circulating bacterial endotoxin during the beginning of acute gram-negative infections. In accordance with this model, Borderas et al. (2008) observed a reduction of the RT in calves after a treatment with a low dose of LPS. In the current study, we assessed metabolic disorders by evaluating biochemical changes. As formulated in different studies (Soriani et al., 2012), the results with an increase or decrease of more than $10 \%$ than the upper or lower limit of the reference values were taken into consideration.

Confirmed metabolic disorders were found in a total of 12 dairy cows (7.14\%), the association between decreased daily rumination time and increased physical activity not being statistically correlated with the development of metabolic disorders, $\mathrm{p}=0.4676$ (Tab. 4). 
Tab. 4. The association between specific combination of decreased daily rumination time and increased physical activity (DRT/PA) and the presence of metabolic disorders (MT)

\begin{tabular}{|c|c|c|c|c|}
\hline \multicolumn{5}{|c|}{ Count } \\
\hline & & \multicolumn{2}{|c|}{ MD } & \multirow{2}{*}{ Total } \\
\hline & & 0 & 1 & \\
\hline \multirow{2}{*}{ DRT/PA } & 0 & 120 & 11 & 131 \\
\hline & 1 & 36 & 1 & 37 \\
\hline \multicolumn{2}{|c|}{ Total } & 156 & 12 & 168 \\
\hline
\end{tabular}

The study shows an extremely significant correlation between the presence of estrus and the increased physical activity and decreased daily rumination time, the implications of this study being important to differentiate between various pathologies. The research does not rule out the association of the two-specific combinations of decrease daily rumination time and increased physical activity with the development of some early stage disorders that do not cause significant changes of biochemical parameters.

\section{CONCLUSIONS}

The conducted study revealed the following conclusions:

1. The statistical assessment between the presence of estrus and decreased daily rumination time demonstrated that a very significant correlation exists, with a p-value $<0.05$ ( $p=$ $0.0369)$.

2. Regarding the correlation between increased physical activity, found in 40 cows and the presence estrus observed in 57 cows it can be stated that there is an extremely significant statistical correlation with a p-value $<0.001$ ( $p=$ 0.0005).

3. The correlation between the specific association of decreased daily rumination time and increased physical activity with the presence of estrus in dairy cows is considered to be extremely significant, with a p-value $<0.005(\mathrm{p}=0.0003)$.

4. The combination between decreased daily rumination time and increased physical activity is not statistically correlated with the development of metabolic disorders, $\mathrm{p}=0.4676$.

5. It remains to be shown if a specific correlation between the association of decreased daily rumination time and increasing physical activity occurs in the early stages of metabolic disorders.

\section{REFERENCES}

1. Adin G, Solomon R, Nikbachat M, Zenou A, Yosef E, Brosh A, Shabtay A, Mabjeesh SJ, Halachmi I, Miron J (2009). Effect of feeding cows in early lactation with diets differing in roughageneutral detergent fi ber content on intake behavior, rumination, and milk production. J Dairy Sci 92:3364-3373.

2. Beauchemin KA, Zelin S, Genner D, Buchanan-Smith JG (1989). An automatic system for quantifi cation of eating and ruminating activities of dairy cattle housed in stalls. J Dairy Sci 72:2746-2759.

3. Beauchemin KA (1991). Ingestion and mastication of feed by dairy cattle. Vet Clin North Am Food Anim Pract.7:439-463.

4. Berka T, Stípkova M, Volek J, Rehák D, Mateju G, Jílek F (2004). Monitoring of physical activity for management of cow reproduction. Czech J Anim Sci, 49, 281-288.

5. Borderas TF, de Passillé AM, Rushen J (2008). Behavior of dairy calves after a low dose of bacterial endotoxin. J Anim Sci 86:2920-2927.

6. Brehme U, Stollberg U, Holz R, Schleusener T (2006). ALT pedometer - a new sensor-aided measurement system for improvement in oestrus detection. Res Agric Eng 52, 1-10.

7. Burfeind $\mathrm{O}$, Schirmann $\mathrm{K}$, von Keyserlingk MAG, Veira DM, Weary DM, Heuwieser W (2011). Technical note: evaluation of a system for monitoring rumination in heifers and calves. J Dairy Sci 94, 426-430.

8. Doron B, Ran S (2010) Rumination Collars: What Can They Tell Us, The First North American Conference on Precision Dairy Management.

9. Kaske M, Beyerbach M, Hailu Y, Gobel W, Wagner S (2002). The assessment of the frequency of chews during rumination enables an estimation of rumination activity in hay-fed sheep. J Anim Physiol Anim Nutr (Berl.) 86:8389.

10. Lindgren $\mathrm{E}$ (2009). Validation of rumination measurement equipment and the role of rumination in dairy cow time budgets. Second cycle, A2E. Uppsala: SLU, Dept. of Animal Nutrition and Management.

11. Lopez H, Satter LD, Wiltbank MC (2004). Relationship between level of milk production and estrous behavior of lactating dairy cows. Anim Reprod Sci 81, 209-223.

12. Luginbuhl, JM, Pond KR, Russ JC, Burns JC (1987). A simple electronic device and computer interface system for monitoring chewing behavior of stall-fed ruminant animals. J Dairy Sci 70:1307-1312.

13. Maekawa M, Beauchemin KA, Christensen A (2002). Effect of concentrate level and feeding management on chewing activities, saliva production, and ruminal $\mathrm{pH}$ of lactating dairy cows. J Dairy Sci 85, 1165-1175.

14. Maltz E, Devir S, Metz JHM, Hogeveen H (1997). The body weight of dairy cows. I. Introductory study into body weight changes in dairy cows as a management aid. Livest Prod Sci 48:175-186 
15. Mondal M, Rajkhowa C, Prakash BS (2006). Relationship of plasma estradiol-17 $\beta$, total estrogen, and progesterone to estrus behaviour in mithin (Bos frontalis) cows. Horm Behav 49, 626-633.

16. Ranasinghe RMSBK, Nakao T, Yamada K, Koike K (2010). Silent ovulation, based on walking activity and milk progesterone concentrations, in Holstein cows housed in a free-stall barn. Theriogenology 73, 942-949.

17. Reith S, Brandt H, Hoy S (2014). Simultaneous analysis of activity and rumination time, based on collar-mounted sensor technology, of dairy cows over the peri-estrus period. Livestock Sci170: 219-227.

18. Reith S, Hoy S (2012). Relationship between daily rumination time and estrus of dairy cows, J Dairy Sci 95(11):6416-20. doi: 10.3168/jds.2012-5316.

19. Schirmann K, von Keyserlingk MAG, Weary DM, Veira DM, Heuwieser W (2009). Technical note: Validation of a system for monitoring rumination in dairy cows. J Dairy Sci 92: 6052-6055.
20. Soriani N, Panella G, Calamari L (2013). Rumination time during the summer season and its relationships with metabolic conditions and milk production. J Dairy Sci 96, 5082-5094.

21. Soriani N, Trevisi E, Calamari L (2012). Relationships between rumination time, metabolic conditions and health status in dairy cows during the transition period. J Anim Sci Jun 28.

22. Yang WZ, Beauchemin KA (2006). Effects of physically effective fi ber on chewing activity and ruminal $\mathrm{pH}$ of dairy cows fed diets based on barley silage. J Dairy Sci 89:217-228.

23. Yániz JL, Santolaria P, Giribet A, López-Gatius F (2006). Factors affecting walking activity at estrus during postpartum period and subsequent fertility in dairy cows. Theriogenology 66, 1943-1950. 